\title{
Evaluating Anaemia Treatment in Associated Diseases in Children in Port Harcourt, Nigeria
}

Chijioke-Nwauche IN*, Origbo CC

Department of Clinical Pharmacy and Management, Faculty of Pharmaceutical Sciences, University of Port Harcourt, Port Harcourt, PMB 5323, Port Harcourt, Rivers State, Nigeria

DOI: $\underline{10.36347 / \text { sajp.2020.v09i07.001 }}$

| Received: 06.06.2020 | Accepted: 13.06.2020 | Published: 04.07.2020

*Corresponding author: Chijioke-Nwauche IN

Abstract

Anaemia is a major global health problem affecting every social class of persons but particularly the low socioeconomic group hence it is more common in poorer countries with the highest proportion of affected people living in Africa. More than half of children below five years of age suffer from anaemia, and a prevalence of $68.3 \%$ was reported in Nigeria in 2016 among children under five. Anaemia causes about one million deaths globally each year with three quarters of these occurring in Africa and Asia. A cross sectional study was carried out in the Paediatric Units of two health establishments in Niger Delta area Nigeria among children of ages 6 months to 15 years admitted between January 2017-December, 2018. Study involved the evaluation of prevalence of anaemia with the associated diseases as well as the treatment pattern of the anaemia. The overall prevalence of anaemia was $18 \%$ in UPTH and $10.4 \%$ in PHC, Aluu. Anaemia was more prevalent among children less than 5 years especially in the age group 2-3 years in both institutions but was not associated with sex. The highest associating disease with anaemia was malaria. Treatment approach used in the present study was in consonance with standard guidelines with the use of haematinics and where necessary blood transfusion was used. Non-adherence to prescribed treatment plan was the highest challenge for obtaining the expected outcome in the treatment of anaemia. The need to address the associated causes is very imperative; therefore, free treatment of malaria particularly for children below 5 years is advocated as a means of reducing anaemia. Involvement of pharmacists in the inpatients services of dispensing and counselling of patients to enable improved awareness and importance of adherence of patients to their medication is strongly recommended.

Keywords: Anaemia, malaria, children, diseases, treatment.

Copyright @ 2020: This is an open-access article distributed under the terms of the Creative Commons Attribution license which permits unrestricted use, distribution, and reproduction in any medium for non-commercial use (NonCommercial, or CC-BY-NC) provided the original author and source are credited.

\section{INTRODUCTION}

A major global health concern affecting every stage of life especially children and pregnant women is anaemia. Anaemia has become a public health issue which affects all social class of persons, both rich and poor but particularly the low socio-economic group hence it is more common in poorer countries with the highest proportion of affected people being in Africa [1]. More than half of children below five years of age suffer from anaemia which has been linked mostly to iron deficiency [2]. In Nigeria, a prevalence of $68.3 \%$ was reported in 2016 among children under five according to World Bank collection of development indicators [3]. Anaemia causes about one million deaths globally each year with three quarters of these occurring in Africa and Asia [4, 5].
The World Health Organization defines anaemia as a situation where a patient is unable to meet the body's physiologic needs as a result of poor oxygen-carrying capacity due to deficiency in red blood cells (RBCs) [6]. This implies a reduced concentration of haemoglobin or packed cell volume (PCV) in the peripheral blood below the expected normal range for sex and age of the individual. Technically speaking, anemia is not a disease, but rather the sign of an underlying basic pathological process, which may function as a compass in the search for the cause, as well as function as a marker in the investigation of underlying pathological process [7]. Symptoms of anaemia include shortness of breath especially on exertion, weakness, lethargy, palpitations. General signs include pallor of mucous membranes or nail beds while specific signs are associated with particular types of anaemia [8]. 
Many factors have been implicated in the cause of anaemia but iron deficiency anaemia has been identified as the primary cause of all anaemia cases [9]. Other causes of anaemia include infectious diseases such as malaria, HIV, tuberculosis, hepatitis $\mathrm{B}$ or $\mathrm{C}$, congenital diseases like sickle cell anaemia (SCA), intestinal helminthiasis, glucose-6 phosphate dehydrogenase deficiency (G6PD) and malnutrition [10-14]. Furthermore, nutritional deficiencies in folic acid and vitamin B12 may lead to ineffective RBC production resulting in anaemia.

In chronic kidney disease conditions (CKD), there is decreased production of erythropoietin, the hormone responsible for production of RBCs leading to its fewer production by the bone marrow, the resultant effect is anaemia due to low levels of haemoglobin. With progressive chronic kidney disease, there is increased tendency of anaemia severity [15]. Anaemia increases mortality in children and also affects their cognitive and physical development especially iron deficiency even up to adolescence $[16,17]$.

Many strategies have been in use for the treatment of anaemia, but of primary importance is the treatment of the underlying cause and subsequent building up of the blood through administration of haematinics or other mineral and vitamin supplements. Since there are many causes of anaemia, treatment guidelines require an integral approach where first of all the cause is addressed and then followed up with the use of medications $[18,19]$.

According to the Nigeria Treatment Guidelines, the objectives of treatment of anaemia include restoration of haemoglobin concentration to normal levels and prevention and treatment of complications. Medications used are primarily haematinics and includes iron, vitamin $\mathrm{B}_{12}$ and folic acid [20]. In severe cases or chronic disorders, blood transfusion of whole blood or red cell concentrate is advocated.

The study was designed to determine the prevalence of anaemia and evaluate treatment pattern of anemia in associated diseases in children 6 months -15 years in a Primary Health Center and a Tertiary Hospital both in Port Harcourt. The outcome of the study will contribute to the existing data on anaemia and may serve as a guide to improve the general management of anaemia in the study area.

\section{MATERIALS AND METHODS}

The study was carried out in the Paediatric Unit of University of Port Harcourt Teaching Hospital and Primary Health Center Omuoko Road, Aluu. The University of Port Harcourt Teaching Hospital (UPTH) is located at Alakahia, a small town at the outskirts of Port Harcourt. Even though, UPTH is a tertiary hospital, it also offers primary and secondary healthcare services with an 800 bed capacity. Port Harcourt is the capital of Rivers state, located in Niger-Delta region of Nigeria. The Primary Health Center Omuoku Road, Aluu is located in Aluu, a semi-urban community located about $5 \mathrm{~km}$ from the present site of the teaching hospital, and was designed to provide health care services in the rural community.

Study was designed in two arms: a retrospective cohort study of anaemia and its treatment among children between 6months and 15 years for the period of Jan, 2017-Dec.2018 and a prospective study of the challenges in the treatment of malaria as reported by the health workers in the study areas. Two methods were employed in collection of data: assessment of patients' case notes and use of questionnaires to harvest information from the health workers.

Case notes of the patients were identified from the Nurses' documentation through identification codes for all anaemia-associated cases in both institutions before retrieving the folders for perusal. The record showed that out of 585 inpatients admitted in the c Unit of UPTH within the study period, $106(18 \%)$ patients had anemia while 30 out of 289 patients had anemia in Primary Health Center within the 2017-2018 period. Besides the demographic data, specific information such as: laboratory results on complete blood count (CBC), diseases associated with anemia, treatment pattern and medications as well as nutritional management employed were also collected.

Inclusion criteria included case notes of patients that met the following criteria (Age; 6 months to 15 years, confirmed diagnosis of anemia and were on admission. Anaemia in this study was defined as packed cell volume PCV less than or equal to $33 \%$ (Hb:11) and classified as follows: mild anaemia (PCV 3033\%/Hb:10-11), moderate anaemia (PCV 21$<30 \% / \mathrm{Hb}: 7-<10)$ or severe anaemia (PCV $<21 \% / \mathrm{Hb}:<7)$ according the diagnostic measure in the health establishments studied and WHO (2011). Case notes of outpatients, persons with age outside 6 months to 15 years and disease conditions not associated with anemia were excluded from the study.

As part of the evaluation of the treatment of anaemia in these institutions, relevant information on the prevalence, classification methods as well as challenges of treatment of anaemia besides demography were collected from health workers in the Paediatric Units of the establishments through a well-structured questionnaire consisting of 24 questions. The spread of the workers consisted of a total of 24 Health Workers comprising of 3 Pharmacists, 12 Nurses, and 1 Physician from the Pediatric Unit of UPTH and 7 Nurses, no physician and 1 pharmacist from the Primary Health Center, Aluu. 


\section{Ethical Approval}

Ethical approval was obtained from the Research and Ethical Committee of the University of Port Harcourt Teaching Hospital (UPTH) with Approval number UPTH/ADM/90/S.B/VOL.XI/801 and Primary Health Center Omuoko Road, Aluu prior to commencement of the study.

\section{RESULTS}

The results obtained from the records entered in the treatment book showed that, out of 585 inpatients in the Paediatrics Unit of UPTH, 106 (18\%) had anaemia while $30(10.4 \%)$ out of 289 patients in Primary Health Center had anaemia within the 20172018 period. The age and sex distribution is as shown in Table-1.

Table-1: Socio-demographic data of patients

\begin{tabular}{|l|l|l|}
\hline & UPTH & PHC \\
\hline Sex & No. of children $(\%)$ & No. of children $(\%)$ \\
\hline Female & $51(48.1)$ & $12(40)$ \\
\hline Male & $55(51.9)$ & $18(60)$ \\
\hline Age & \multicolumn{2}{|l|}{} \\
\hline 6months -1year & $25(23.6)$ & $3(10)$ \\
\hline $2-3$ years & $28(26.4)$ & $7(23.3)$ \\
\hline $4-5$ years & $13(12.3)$ & $5(16)$ \\
\hline $6-7$ year & $15(14.2)$ & $3(10)$ \\
\hline $8-9$ years & $3(2.8)$ & $3(10)$ \\
\hline $10-11$ years & $5(4.7)$ & $4(13.3)$ \\
\hline $12-13$ years & $8(7.5)$ & $4(13.3)$ \\
\hline $14-15$ years & $9(8.5)$ & $0(0 \%)$ \\
\hline
\end{tabular}

From the results, the 2-3year age group has the highest number of patients with anaemia in both establishments with values of 28/106 (26.4\%) and 7/30 $(23.3 \%)$ in UPTH and PHC respectively.

Out of the 106 patients recorded in the book, only 84 case notes were available for assessment in UPTH, and 28 of out of the 30 were available in Primary Health Center. Based on the classification of anaemia, results show the prevalence of anaemia in
UPTH to be mild, moderate and severe: 10/84 (12\%), $38 / 84(45 \%)$ and $36 / 84(43 \%)$ respectively. The review of the case folders from the PHC, showed no details of the anaemia cases beyond the causes because they were all referred to the teaching hospital for treatment.

Results obtained shows malaria as the highest disease causing anemia from both health institutions accounting for $28.6 \%$ and $27.0 \%$ in UPTH and PHC respectively and the least to be tuberculosis (Table-2).

Table-2: Prevalence of anaemia and the associated diseases

\begin{tabular}{|l|l|l|}
\hline Diseases & UPTH & PHC \\
\hline Malaria & $\begin{array}{l}\text { Anaemic cases } \\
\mathbf{N = 1 2 6 )}, \mathbf{n}(\%)\end{array}$ & $\begin{array}{c}\text { Anaemic cases } \\
(\mathbf{N}=37), \mathbf{n}(\%)\end{array}$ \\
\hline Sickle Cell Disease (SCD) & $36(28.6)$ & $10(27.0 \%)$ \\
\hline Kidney Disease (AKD) & $11(14.3)$ & $0(0)$ \\
\hline HIV & $14(11.0)$ & $2(5.4)$ \\
\hline Septicaemia & $7(5.6)$ & $1(2.7)$ \\
\hline Bronchopneumonia & $8(6.3)$ & $2(5.4)$ \\
\hline Dysentry and Diarrhoea & $1(0.8)$ & $1(2.7)$ \\
\hline Co-morbidity (CHD, Diabetes) & $4(3.1)$ & $8(21.7)$ \\
\hline Meningitis & $3(2.4)$ & $0(0)$ \\
\hline Cancer & $2(1.6)$ & $0(0)$ \\
\hline Peptic Ulcer & $1(0.8)$ & $0(0)$ \\
\hline Gastroenteritis & $0(0)$ & $0(0)$ \\
\hline Measles & $0(0)$ & $2(5.4)$ \\
\hline Bleeding gum & $0(0)$ & $1(2.7)$ \\
\hline Malnutrition & $18(14.3)$ & $1(2.7)$ \\
\hline Tuberculosis & $1(0.8)$ & $6(16.2)$ \\
\hline Febrile convulsion & $1(0.8)$ & $1(2.7)$ \\
\hline Acute Respiratory Disease & $1(0.8)$ & $0(0)$ \\
\hline
\end{tabular}

* some patients had multiple causative factors, hence the number of recorded diseases is more than the number of the patients. 


\section{Pattern of treatment and management of anemia}

Treatment and management of anemia in UPTH commences most frequently at PCV levels less than $30 \%$. Blood transfusion was commenced for patients with PCV less than $21 \%$. The percentage of patients that received blood transfusion was $43 \%$ corresponding to the 36 patients with severe anaemia, out of which 27 received sedimented red blood cells and 9 received whole blood. In addition to the blood transfusion, these patients were also treated with medications. The rest of the patients were treated with medications alone and nutritional support.

On the other hand, there was no record of blood transfusion for patients in the Primary Health Centre due to inadequate facilities for management of moderate to severe anemia hence patients who needed blood transfusion were rather referred to the teaching hospital.

Medications that were used for the treatment of anaemia were ferrous salts, folic acid and multivitamins. About five different classes/types of drugs were used for the management of anemia in both institutions. These medications were mostly haematinics and usually marketed as combination products examples of which are Dioscovite ${ }^{\circledR}$ (contains Thiocyanate), Astyfer ${ }^{\circledR}$ (cyanocobalamin, ferrous fumarate, folic acid, pyridoxine), Astymin ${ }^{\circledR}$ (calcium panthothenate, folic acid and vitamins), Ranferon $12^{\circledR}$ (folic acid, iron, Vit B12, Vit. C, Zinc). About 3 (2\%) of the patients were treated with Erythropoeitin in UPTH. An important aspect of management of anaemia in children as observed from the study is diet. Mothers and care givers were advised to give balanced diets comprising of proteins and vegetables which help build up the nutritional status of the patients and consequently improve the heamatological parameters.

Treatment outcome from the results show that there was an improvement of the anemia in UPTH after treatment as shown in Table-3.

Table-3: Treatment Outcome

\begin{tabular}{|c|c|c|}
\hline PCV Before (\%) & PCV After (\%) & Frequency (\%) \\
\hline $30-33 \%$ & $\geq 37 \%$ & $10(11.9)$ \\
\hline $20-29 \%$ & $\geq 37 \%$ & $27(32.1)$ \\
\hline $20-29 \%$ & $>29 \%$ & $11(13.1)$ \\
\hline $13-19 \%$ & $\geq 37 \%$ & $9(10.7)$ \\
\hline $13-19 \%$ & $\geq 20 \%$ & $19(22.7)$ \\
\hline$<13 \%$ & $\geq 20 \%$ & $8(9.5)$ \\
\hline \multicolumn{2}{|c|}{ Total } & 84 \\
\hline
\end{tabular}

Analysis of the questionnaire responses by the health workers revealed various challenges encountered in the management of anaemia. The highest ranking on the list is non-adherence of patients to medications, in both UPTH and PHC accounting for $33.3 \%$ and $30.0 \%$ respectively. Other challenges listed include out of stock of the medications in the pharmacies, malnutrition, financial constraints leading to inability to afford treatment, time constraints on the part of the pharmacists to give proper counseling to the patients and lastly, treatment failure of the underlying disease.

\section{DISCUSSION}

The study has shown the prevalence pattern of anaemia among admitted children in Primary Health Centre, Aluu and University of Port Teaching Hospital in the studied period (Jan, 2017-Dec 2018). The overall prevalence of anaemia was $18 \%$ in UPTH and $10.4 \%$ in PHC. Anaemia was not associated with sex or gender. The percentage of severe anaemia differs from the $31.2 \%$ value obtained among anaemic children admitted in a secondary health facility in the western part of Nigeria [21]. Results established that anemia was more prevalent among children less than 5 years especially in the age group 2-3 years in both institutions. This is in consonance with earlier study in Enugu, South East Nigeria [22] which established highest prevalence of anaemia in children less than 5 years and particularly for children between 13-36 months.

The highest cause of anaemia in both establishments was malaria Earlier studies have established malaria as the primary cause of anaemia in African children [22-25]. Severe haemolysis is associated with malarial infection especially Plasmodium falciparum infection which is responsible for most malignant form of malaria in sub-Saharan Africa [26]. Children in endemic region with stable malaria transmission especially those under five years are among the most vulnerable people to malaria infection because they do not have immunity which is often acquired over time with several exposures to malaria parasite through mosquito bites [27].

Another disease implicated in causing anaemia from the study is sickle cell disease (SCD) in keeping with a study from Tanzania and western Nigeria [23, 21]. The sickle shaped cells as obtained in SCD are usually destroyed more easily than the normal red blood cells such that persons with SCD tend to be anaemic. The situation is made worse in malnourished cases and 
in the present study, malnutrion was another major cause of anaemia among the children. Many studies have established association between malnutrition and anaemia in children [28, 23, 24].

Malnutrition in children is one of the greatest public health challenges in Africa and the greatest risk factor of disease burden globally [29]. Malnourished children have been found to be more susceptible to communicable diseases such as malaria, HIV, helminthiasis etc due to reduced immune response [3032].

Other anaemia-associated diseases in the study are retroviral disease (HIV), bronchopneumonia, septicaemia, meningitis, diabetes, kidney diseases and cancers. Anaemia is one of the major characteristics of HIV infection and this may occur either through decreased RBC production, increased RBC destruction or ineffective RBC production [33]. The interstitial cells of the kidney make erythropoietin, the hormone responsible for producing red blood cells. It is therefore not a surprise that one of the associated diseases in anaemia is kidney disease.

Treatment approach used in the present study is in consonance with standard guideline. According to the Nigeria Standard Treatment Guidelines [20], the objectives of treatment was to restore haemoglobin concentration to normal levels. In order to achieve this, haematinics which includes iron, folic acid and vitamin $\mathrm{B}_{12}$ depending on the specific need should be used for treatment of moderate anaemia while blood transfusion was indicated for severe anaemia and conditions such as septicaemia. In the present study, $43 \%$ of the patients who had severe anaemia received blood transfusion either as whole blood or as platelets while the rest were treated with haematinics. Severe anaemia requiring blood transfusion accounts for majority of admissions in emergencies in Nigeria $[34,35]$. The outcome of the treatment was evidenced by the general increase in the haemoglobin concentrations.

Proper nutrition and diet have also been advocated as treatment options for anaemia in children. So remedying the nutritional imbalance will improve the health status and invariably improve the haemoglobin of the children. For sickle cell anaemia, treatment may involve hydrating the patients either through oral or intravenous fluids to reduce pain, administration of folic acid and sometimes blood transfusion in order to prevent complications [36].

For effective treatment of anaemia in children, apart from the importance of following the treatment strategies, there is need for adherence to the prescribed treatment. Non-adherence is a major limitation to achieving therapeutic goal because it reduces patients' optimal benefit from medication resulting in increased morbidity and mortality [37]. The present study has shown patients' non-adherence to prescribed treatment plan as the highest challenge for obtaining the expected outcome in the treatment of anaemia. There is need for proper education and enlightenment on the importance of adherence to prescribed medications. Strategies to improve this may include awareness and increased contact time of patients with pharmacists to ensure proper pharmaceutical care. This insufficient time with the pharmacists was also listed as one of the challenges in the proper management of anaemia.

Patients' non-adherence to medications could be worsened because of insufficient information resulting from shorter dispensing and contact time of the patient with the pharmacist. We could not ascertain the contact time each patient/caregiver had with the pharmacist because it was not within the scope of present study. Moreover, where the subjects are inpatients as in the present settings, it is the nurses that dispense and administer the drugs to the patients and not the pharmacists. This method of dispensing portends a potential problem because the staff involved are not equipped to deliver adequate pharmaceutical care to the patients. To ensure rational drug, there is need to adhere to patient care indicators which includes amongst other things a minimum of 3 minutes for dispensing and counseling by a pharmacist [38].

Health system failure which in this case was highlighted by out of stock syndrome in the pharmacy accounted for about $20.3 \%$ (the second highest) of the challenges. The success of any nation's health policy is ineffective without the availability of good quality and affordable medicines.

In conclusion, the study has established anaemia-associated diseases to be similar to previous studies. The need to address these common issues is therefore very imperative. Since malaria is a primary cause of anaemia, free treatment of malaria particularly for children below 5 years is advocated as a means of reducing anaemia in children. Involvement of pharmacists in the inpatients services of dispensing and counseling of patients to enable improved awareness and importance of adherence of patients to their medication is strongly recommended.

Conflict of Interest: The authors declare no conflict of interest.

\section{REFERENCES}

1. WHO. 'Worldwide prevalence of anemia 1993 2005,'WHO global database on anemia, 2008. accessed (16 June, 2019).

2. Rolando YW. Anemia in Children-Prevalence Around the World. 2018. Available at https://www.worldatlas.com/articles/countrieswith-highest-rates-of-anemia-amongchildren.html. Accessed (16 August, 2019) 
3. Trading Economics. Nigeria-Prevalence of Anaemia among Children (\% Of Children Under 5). 2020. Available at: https://tradingeconomics.com/nigeria/prevalenceof-anemia-among-children-percent-of-childrenunder-5-wb-data.html. Accessed $5^{\text {th }}$ June, 2020.

4. Benoist BD, McLean E, Egli I, Cogswell M. Worldwide prevalence of anemia 1993-2005: WHO Global Database on Anemia. Geneva, Switzerland: World Health Organization; 2008.

5. World Health Organization. The Global Prevalence of Anaemia in 2011. Geneva, Switzerland: World Health Organization, 2015.

6. WHO. 'Hemoglobin concentration for the diagnosis of anemia and assessment of severity', WHO, 2011. https://www.who.int/topics/anaemia/en/. Accessed 10/01/2020).

7. Novak C, Forbes K. Approach to pediatric anemia and Pallor, Pedscases, 2015. www.pedcases.com/podcasts accessed (22 August, 2019)

8. Hoffbrand AV, Moss PAH. Essential Haematology. Seventh Edition. Wiley Blackwell, 2016.

9. Kassebaum NJ, Jasrasaria R, Naghavi M, Wulf SK, Johns N, Lozano R, Regan M, Weatherall D, Chou DP, Eisele TP, Flaxman SR. A systematic analysis of global anemia burden from 1990 to 2010. Blood. 2014 Jan 30;123(5):615-24.

10. Robert T. Anemia of inflammation and chronic disease' National Institution of Diabetes and digestive and kidney diseases (NIDDK): 2019. www.nddk.nih.gov.health-information/blooddiseases/anemia-inflammationchronicdisease\#causes accessed (3 September, 2019)

11. Fleming A. Anaemia in Northern Nigeria and two South African cities. In: Nestel P, ed. Iron Interventions for Child Survival. Proceedings, May 17-18, 1995, London. Arlington, USA: John Snow (JSI) Opportunities for Micronutrient Intervention (OMNI), 1995:139-142.

12. Callis JC, Phiri KS, Faragher EB. Severe anaemia in Malawian children. $\mathrm{N}$ Eng $\mathrm{J}$ Med, 2008;358(9):888-899.

[http://dx.doi.org.10.1056/NEJMoa072727]

13. Schellenberg D, Schellenberg JR, Mushi A, Savigny DD, Mgalula L, Mbuya C, Victora CG. The silent burden of anaemia in Tanzanian children: a community-based study. Bulletin of the World Health Organization. 2003;81:581-90.

14. Rahman MS, Mushfiquee M, Masud MS, Howlader T. Association between malnutrition and anemia in under-five children and women of reproductive age: Evidence from Bangladesh Demographic and Health Survey 2011. PLoS ONE, 2019; 14(7): e0219170. https://doi.org/ 10.1371/journal.pone.0219170.
15. Shaikh H, Aeddula NR. Anemia of Chronic Renal Disease. StatPearls Publishing; 2020.

16. Lozoff B, Jimenez E, Hagen J, Mollen E, Wolf AW. Poorer behavioral and developmental outcome more than 10 years after treatment for iron deficiency in infancy. Pediatrics. 2000;105:E51.

17. Grantham-McGregor S, Ani C. A review of studies on the effect of iron deficiency on cognitive development in children. $J$ Nutr. 2001;131:649S-666S.

18. WHO: Guidelines for the treatment of malaria. Geneva, Roll Back Malaria Department, World Health Organization, 2006 (WHO/HTM/MAL/2006.1108).

19. Crompton DWT, eds. Controlling disease due to helminth infections. Geneva, World Health Organization, 2003.

20. Federal Ministry of Health. Standard Treatment Guidelines Nigeria. 2008.

21. Ogunlesi T, Fetuga B, Olowonyo M, Adekoya A, Adetola O, Ajetunmobi A. Severe Childhood Anaemia and Blood Transfusion in a Nigerian Secondary Level Facility. Journal of Tropical Pediatrics, 2016, 62, 107-115.

22. Ughasoro MD, Emodi IJ, Okafor HU, Ibe BC. Prevalence and risk factors of anaemia in paediatric patients in South-East Nigeria. South African Journal of Child Health. 2015;9(1):14-7.

23. Simbauranga RH, Kamugisha E, Hokororo A, Kidenya BR, Makani J. Prevalence and factors associated with severe anaemia amongst underfive children hospitalized at Bugando Medical Centre, Mwanza, Tanzania. BMC Hematology, 2015; 15:13

24. Ncogo P, Romay-Barja M, Benito A, Aparicio P, Nseng G, Berzosa P, Santana-Morales MA, Riloha M, Valladares B, Herrador Z. Prevalence of anemia and associated factors in children living in urban and rural settings from Bata District, Equatorial Guinea, 2013. PloS one. 2017;12(5):e0176613.

25. Jiya NM, Yusuf TY, Airede KI. Severe anaemia in childhood in Sokoto State, Nigeria. Sahel Medical Journal, 2006, 9(2):52-55

26. Urdaneta L, Lal A, Barnabe C, Oury B, Goldman I, Ayala FJ, Tibayrence M. Evidence for clonal propagation in natural isolates of Plasmodium falciparum from Venezuela. Proc Natl Acad Sci U, 2001. S A, 2001;98, 6725-9.

27. White NJ. Anaemia and malaria. Malar J, 2018;17:371. https://doi.org/10.1186/s12936018-2509-9

28. Osazuwa F and Oguntade MA. Contribution of malnutrition and malaria to anemia in children in rural communities of Edo state, Nigeria. North American Journal of Medical Sciences, 2010; 2(11):532-6.

29. Ezzati M, Lopez AD, Rodgers A, Vander Hoorn S, Murray CJ. Comparative Risk Assessment 
Collaborating Group Selected major risk factors and global and regional burden of disease. Lancet, 2002;360:1347-1360.

30. Stoltzfus RJ, Chway HM, Montresor A, Tielsch JM, Jape JK, Albonico M, Savioli L. Low dose daily iron supplementation improves iron status and appetite but not anemia, whereas quarterly anthelminthic treatment improves growth, appetite and anemia in Zanzibari preschool children. The Journal of nutrition. 2004 Feb 1;134(2):348-56.

31. Ehrhardt S, Burchard GD, Mantel C, Cramer JP, Kaiser S, Kubo M, Otchwemah RN, Bienzle U, Mockenhaupt FP. Malaria, anemia, and malnutrition in African children-defining intervention priorities. The Journal of infectious diseases. 2006 Jul 1;194(1):108-14.

32. Fergusson P, Tomkins A. HIV prevalence and mortality among children undergoing treatment for severe acute malnutrition in sub-Saharan Africa: a systematic review and meta-analysis. Trans R Soc Trop Med Hyg. 2009; 103:541-8.

33. Volberding PA, Levine AM, Dieterich D, Mildvan D, Mitsuyasu R, and Saag M. Anemia in HIV Infection: Clinical Impact and Evidence-Based
Management Strategies. Clinical Infectious Diseases, 2004; 38:1454-63.

34. Adegoke S, Ayansanwo A, Oluwayemi I, Okeniyi J. Determinants of mortality in Nigerian children with severe anaemia. South Afr Med J, 2010;102:807-10.

35. Muoneke VU, Ibekwe RC, Nebe-Agumadu HU, Ibe BC. Factors associated with mortality in under-five children with severe anemia in Ebonyi, Nigeria. Indian Pediatr, 2012;49:119-23.

36. Federal Ministry of Health (FMOH). National Guideline for the Control and Management of Sickle Cell Disease. 2014. Available at http://scsn.com.ng/wpcontent/uploads/2014/11/National-Guideline-forthe-Control-and-Management-of-Sickle-CellDisease-pdf. Accessed, $16^{\text {th }}$ Nov, 2019.

37. Sokol MC, McGuigan KA, Verbrugge RR, Epstein RS. Impact of medication adherence on hospitalization risk and healthcare cost. Med Care. 2005;43(6):521-530

38. WHO Policy Perspectives on Medicine; Promoting rational use of medicines; Core components, (2002), September, Geneva. Available at http://apps.who.int.medicinedocs/en/d/h/Jh3011e/ 